\title{
Measurements and fire simulation models in road tunnels
}

\author{
Peter Danišovič ${ }^{1, *}$, Juraj Šámek $^{1}$, Michal Hodoň ${ }^{2}$, Ján Glasa $^{3}$, Peter Weisenpacher $^{3}$ and \\ Lukáš Valášek \\ ${ }^{1}$ University of Žilina, Faculty of Civil Engineering, Univerzitná 8215/1, 01026 Žilina, Slovakia \\ ${ }^{2}$ University of Žilina, Faculty of Management Science and Informatics, Univerzitná 8215/1, 01026 \\ Žilina, Slovakia \\ ${ }^{3}$ Institute of Informatics, Slovak Academy of Sciences, Dúbravská cesta 9, 84507 Bratislava, Slovakia
}

\begin{abstract}
Ventilation system of road tunnel is one of the most important parts of the tunnel safety equipment, especially in view of the emergency event in the tunnel with fire. Last year we presented the testing and the first in situ measurements of our project entitled "Models of formation and spread of fire to increase safety of road tunnels". With regard to our project schedule we performed also the second in situ experiment. Other part of this paper deals with computer simulations of fires of a selected Slovak road tunnel.
\end{abstract}

\section{Introduction}

Operation and Maintenance of road tunnel is very complicated matter from safety point of view. For these reasons, the idea of Tunnel Traffic \& Operation Simulator (Simulator) was created in 2009, to solve various problems in road tunnels operation. In cooperation with National Motorway Company (NMC, sole administrator of Slovak road tunnels) we realised project of unique device "Simulator". Because the tunnel ventilation system and managing of the ventilation system during the fire is very difficult matter we decided to realize another one project. In cooperation with Institute of Informatics of Slovak Academy of Sciences we deal with investigation of models of formation and spread of fire in road tunnels. Project title is "Models of formation and spread of fire to increase safety of road tunnels. Some basic information about the project:

- develop a series of computer simulations of selected types of fires in selected road tunnels managed by NMC according to negotiated scenarios using the Fire Dynamics Simulator (FDS) fire simulation program system,

- carry out thorough analysis and visualization of the simulation results,

- create a series of visualizations of results of computer simulation of fires in a virtual tunnel of Tunnel Traffic \& Operation Simulator (TTOS) using the FDS system,

\footnotetext{
* Corresponding author: peter.danisovic@,fstav.uniza.sk
} 
- $\quad$ fill up the database of Slovak road tunnels incidents with analysis and statistical processing of the data,

- conduct a series of full-scale fire experiments in a single- and two-tube highway tunnel managed by NMC.

The project is specifically focused on the smoke stratification investigation and the impact of ventilation on maintaining and disruption of stratification.

\section{Measurements in tunnel}

In the first phase of our project, we have performed testing measurement and first in situ measurement. Both measurements were published and presented at Russian-Slovak-Polish Seminar in Warsaw 2017. In the second phase, we focused on preparation and realization of second in situ measurements in Považský Chlmec tunnel. A lot of measurements were performed by Mr. Zaleňák (designer of ventilation system of tunnel), e.g. longitudinal ventilation tests, control and calibration of air flow and opacity meters. Within comprehensive tests of tunnel before handing over to the administrator following tests were performed:

- ventilation control during normal operation,

- ventilation control at fire time,

- parallel tunnel ventilation,

- ventilation of emergency exits,

- time to achieve ventilation targets.

Data from comprehensive tests cannot be published but will be presented at conference. All measures data are available to solve the project and have been used for simulations (see chapter 3).

But other measurements we performed due to needs of the project. We prepared supplementary measurements of air flow velocity and direction at both tunnel portals (Fig. 1) which were measured during tunnel comprehensive tests. They can influence the airflow in the tunnel. Recorded data are used to calibration and clarification of computer simulations. Tunnel Považský Chlmec is two-tube road tunnel with unidirectional operation. The length of tunnel is about $2250 \mathrm{~m}$. It is the newest road tunnel in Slovakia, so also equipped with all modern technology. The implemented longitudinal ventilation system consists of five (right tube) and six (left tube) couples of jet fans with frequency converter. Operation of longitudinal ventilation system in two-tube road tunnel is completely different compared to longitudinal ventilation system of one-tube road tunnel. 


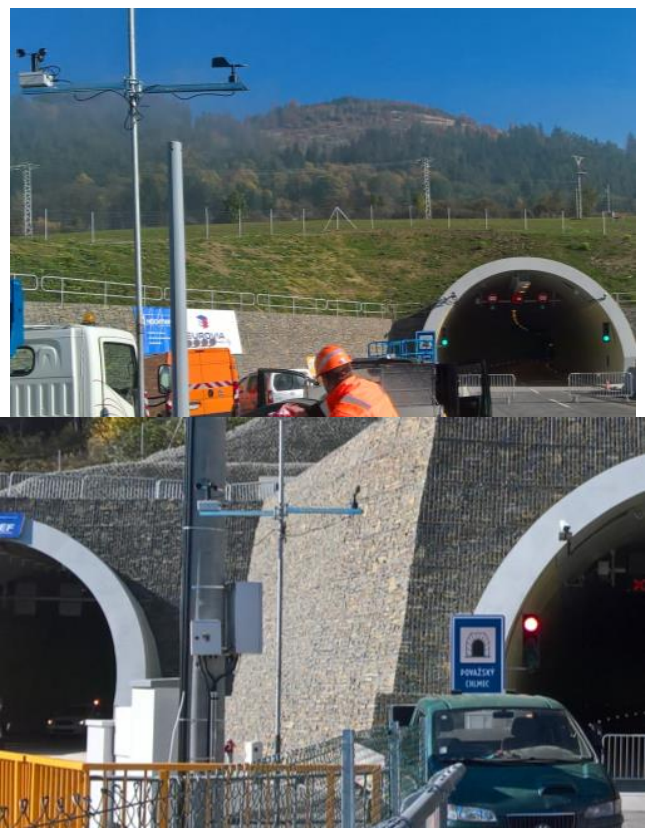

Fig. 1. Our measuring devices at both tunnel portals.

\section{Tunnel fire simulation models}

The aim of the project is to prepare a series of computer simulations of fires in the Povazsky Chlmec tunnel and to validate them using experimental data from onsite tunnel measurements. For the fire modelling we use the FDS (Fire Dynamics Simulator) system which is the well-known advanced free open-source software for simulation of fires in various environments with a fire field model implemented [1-4]. The system is based on CFD (Computational Fluid Dynamics). FDS numerically solves a form of Navier-Stokes equations for low-speed fire-induced flows with the emphasis on smoke propagation and heat transfer from fire. Mathematical model of the fire is based on partial differential equations corresponding to the mass, momentum, energy and species conservation laws, and equation of state. These equations are modified and simplified, and then discretized and numerically resolved on regular three dimensional orthogonal meshes using second-order accurate finite differences scheme. The FDS strongpoint is realistic flow modelling implemented by efficient numerical scheme solving partial differential equations on regular 3D computational meshes.

Research on applicability of FDS for modelling fires in the Povazsky Chlmec tunnel utilizes knowledge obtained during the validation of fire simulations for the Polana highway tunnel carried out under this research project. In this section we illustrate the impact of slope on smoke spread in tunnel by simulation of a fire in two tunnels that differ in this parameter. We consider the Polana tunnel model and a model of an experimental tunnel with the same parameters but different slope.

The Polana tunnel $[5,6]$ is a bi-directional highway tunnel with $2 \%$ slope and two laybys. The tunnel has a standard horseshoe cross-section and dimensions of $900 \times 10 \times 6.8 \mathrm{~m}$ (length $\mathrm{x}$ width $\mathrm{x}$ height). It is equipped with 4 pairs of axial jet fans, located 100 and 200 $\mathrm{m}$ far from the tunnel portals at $5.4 \mathrm{~m}$ height above the road. The tunnel is equipped with measuring and detection devices standard for modern road tunnels in the European Union (flow velocity, temperature and optical density measurement, smoke detection, camera 
surveillance, etc.). The Polana tunnel model for computer simulation by FDS was developed, tested and validated using experimental data from fire tests conducted in the tunnel in 2017. The experimental tunnel under consideration differs from the Polana tunnel in slope ( $2 \%$ slope along the first $450 \mathrm{~m} ;-2 \%$ slope along the remaining $450 \mathrm{~m}$ ). Thus, the Polana tunnel represents a tunnel with constant slope and the experimental $900 \mathrm{~m}$ long tunnel represents a tunnel with variable slope (ascending and descending, similar as in the Povazsky Chlmec tunnel).

In both tunnels we conducted a simulation of a $5 \mathrm{MW}$ fire located $430 \mathrm{~m}$ from the left portal. The fire source was represented by a 1 x $1 \mathrm{~m}$ area burning with the $5000 \mathrm{~kW} / \mathrm{m} 2$ HRRPUA (Heat Release Rate per Unit Area). The fire was initiated at the beginning of the simulation and burnt for $180 \mathrm{~s}$ until the end of the simulation. We considered $2 \mathrm{~m} / \mathrm{s}$ natural airflow towards the right tunnel portal achieved by setting the value of pressure difference on portals (DYNAMIC_PRESSURE $=12 \mathrm{~Pa}$ ). The parallel MPI model was used to parallelize the calculation. The computational domain was divided into 12 computational meshes with $30 \mathrm{~cm}$ resolution (Table 1). The simulations were carried out on the SIVVP computer cluster at the Institute of Informatics of Slovak Academy of Sciences in Bratislava using 12 computational cores (single node) of the cluster.

Table 1. Computational domain decomposition and simulations duration: $\mathbf{N C}$ is the total number of cells in the simulation, $\mathbf{N M}$ is the number of computational meshes, $\mathbf{N C M}$ is the number of cells per mesh, $\mathbf{t}$ is the total computational time.

\begin{tabular}{|c|c|c|c|c|}
\hline Slope & NC & NM & NCM & t \\
\hline $2 \%$ & 4860000 & 12 & 405000 & $51512 \mathrm{~s}$ \\
\hline$+2 \% /-2 \%$ & 4860000 & 12 & 405000 & $51856 \mathrm{~s}$ \\
\hline
\end{tabular}

Figures 2-4 show the smoke spread in the Polana tunnel and the experimental tunnel at the 138 and $180 \mathrm{~s}$ to the fire. The considered times correspond to the time when smoke reached the position of the 4 th jet fans pair and the right portal in the Polana tunnel.

Fig. 2. Smoke spread in the Polana tunnel (the first 2 pictures) and in the experimental tunnel (the next 2 pictures) at the 138 and $180 \mathrm{~s}$ to the fire.
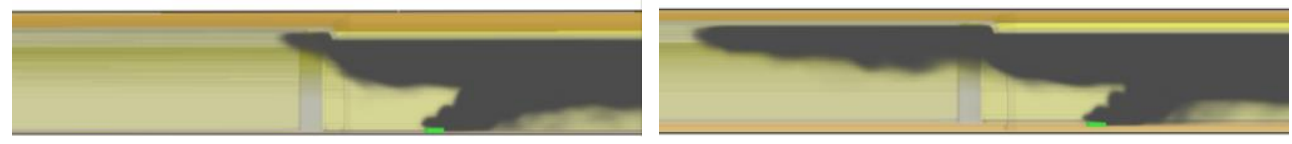

Fig. 3. 3D visualization of smoke backlayering at the end of simulation in the Polana tunnel (left) and the experimental tunnel (right). 

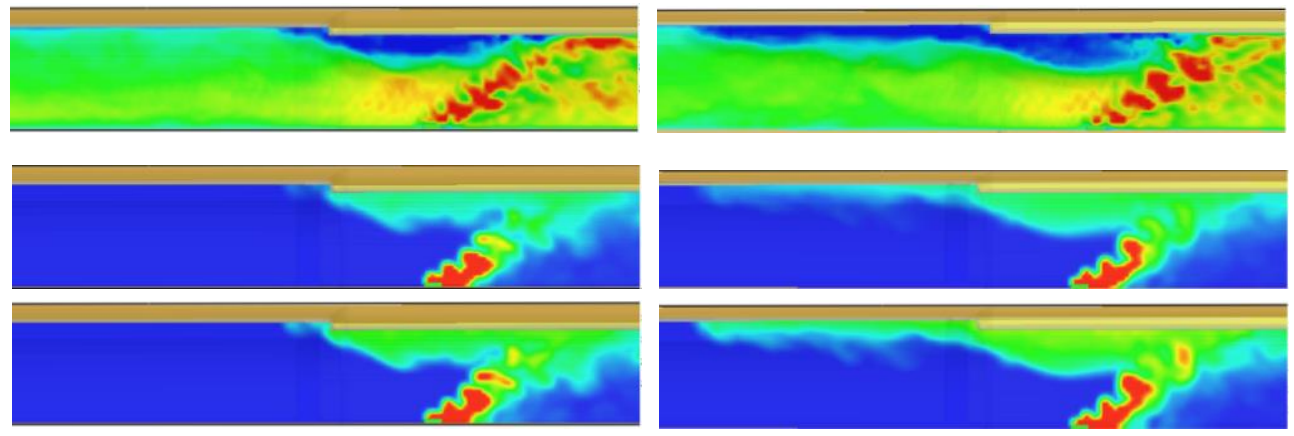

Fig. 4. 2D visualization of airflow velocity, temperature and optical density at the end of simulation in the Polana tunnel (left) and the experimental tunnel (right): vertical slice passing through the tunnel centre; colour schemes for the airflow velocity, temperature and optical density for the Polana tunnel represent the values ranging from -0.52 to $4.40 \mathrm{~m} / \mathrm{s}$, from 4.78 to $198^{\circ} \mathrm{C}$ and from 0 to $3.92 / \mathrm{m}$, respectively, and the corresponding colour schemes for the experimental tunnel represent the values ranging from -0.65 to $4.35 \mathrm{~m} / \mathrm{s}$, from 4.80 to $205^{\circ} \mathrm{C}$ and from 0 to $4 / \mathrm{m}$, respectively.

Table 2 shows the times at which the front of smoke layer reaches selected important positions in the tunnel (the distance of the tunnel centre, lay-by, the 3rd jet fans pair and the 4 th jet fans pair from the fire source).

Table 2. Simulations evaluation: $\mathbf{t 1}, \mathbf{t} \mathbf{2}, \mathbf{t} \mathbf{3}$ and $\mathbf{t} \mathbf{4}$ is the time in which smoke layer reached the position P1, P2, P3 and P4, respectively; P1, P2, P3 and P4 is the distance of the tunnel centre, lay-by, $3^{\text {rd }}$ jet fans pair and $4^{\text {th }}$ jet fans pair, respectively, from the fire source.

\begin{tabular}{|c|c|c|c|c|c|c|c|c|}
\hline Slope & $\mathbf{t 1}$ & $\mathbf{P 1}$ & $\mathbf{t 2}$ & $\mathbf{P 2}$ & $\mathbf{t 3}$ & $\mathbf{P 3}$ & $\mathbf{t 4}$ & $\mathbf{P 4}$ \\
\hline$+2 \%$ & $6 \mathrm{~s}$ & $20 \mathrm{~m}$ & $70 \mathrm{~s}$ & $205 \mathrm{~m}$ & $104 \mathrm{~s}$ & $284 \mathrm{~m}$ & $138 \mathrm{~s}$ & $371 \mathrm{~m}$ \\
\hline$+2 \% /-2 \%$ & $6 \mathrm{~s}$ & $20 \mathrm{~m}$ & $75 \mathrm{~s}$ & $205 \mathrm{~m}$ & $115 \mathrm{~s}$ & $284 \mathrm{~m}$ & $155 \mathrm{~s}$ & $371 \mathrm{~m}$ \\
\hline
\end{tabular}

Figures 2-4 and Table 2 illustrate that the buoyancy force of fire accelerates the smoke spread (and the natural airflow) in ascending tunnel (the Polana tunnel). In the tunnel with variable slope (ascending and descending) the buoyancy force of fire accelerates the smoke spread in ascending direction (as in the previous case), however, later it slows down the smoke spread in descending part of the tunnel. In ascending tunnel, only limited backlayering can be observed. In tunnel with variable slope a more notable backlayering can be observed, however, its velocity is relatively low.

\section{Conclusion}

In this paper measurements of airflow velocity and direction at tunnel portals are illustrated. Data from comprehensive tests of ventilation will be presented at conference. Simulations presented in $3^{\text {rd }}$ chapter are very important to understand the smoke spread in tunnel which can be very useful for operators of road tunnels and last but not least for road tunnel users.

The authors would like to thank to Mr. P. Schmidt (National Motorway Company) and Mr. Štefan Želeñák (Upper Nitra Mines Prievidza) for their cooperation. This work was supported by the Slovak Research and Development Agency APVV (project No. APVV-15-0340). 


\section{References}

1. K. McGrattan, S. Hostikka, R. McDermott, J. Floyd, C. Weinschenk, K. Overholt, Fire Dynamics Simulator. Technical Reference Guide, $\mathbf{6}^{\text {th }}$ edition (2017)

2. K. McGrattan, S. Hostikka, R. McDermott, J. Floyd, C. Weinschenk, K. Overholt, Fire Dynamics Simulator, User's Guide, $\mathbf{6}^{\text {th }}$ edition (2017)

3. P. Weisenpacher, J. Glasa, L. Halada, Parallel Computation of Smoke Movement During a Car Park Fire, Computing and Informatics, 35, 6 1416-1437 (2016)

4. L. Valasek, J. Glasa, On Realization of Cinema Hall Fire Simulation Using Fire Dynamics Simulator, Computing and Informatics, 36, 4 971-1000 (2017)

5. P. Danisovic, J. Glasa, P. Weisenpacher, L. Valasek, Models of formation and spread of fire to increase safety of road tunnels, MATEC Web of Conferences, 117, 00034 (2017)

6. P. Danisovic, J. Sramek, M. Hodon, M. Hudik, Testing measurements of airflow velocity in road tunnels MATEC Web of Conferences, 117, 00035 (2017) 